\title{
PRESEPSI KUALITAS PRODUK, BRAND AWARENESS DAN CELEBRITY ENDORSEMENT TERHADAP MINAT BELI OPPO SMARTPHONE PADA MAHASISWA FAKULTAS EKONOMI UNIBA SURAKARTA
}

\author{
Ayu Intan Pratiwi, Bambang Mursito, Eny Kustiyah \\ Fakultas Ekonomi Manajemen Universitas Islam Batik Surakarta \\ Email: ayuintanpratiwi55@gmail.com
}

\begin{abstract}
This study aims to determine the effect of Product Quality, Brand Awareness and Celebrity Endorsement on the Opposition of Buying Oppo Smartphones on Students of the Faculty of Economics, UNIBA Surakarta. This type of research uses quantitative methods, the population taken in this study were students of Surakarta Samples used in this study were 80 people sampling techniques using Convenience sampling techniques. Data analysis techniques in this study used multiple Linear analysis techniques. F test results state that Product Quality, Brand Awarenesss and Celebrity Endorsement simultaneously and significantly influence the Oppo Smartphone Interest in the Faculty of Economics, UNIBA Surakarta. while based on the test stated that partially the quality of the product had a positive significant effect on the Purchase Oppo Smartphone Interest in the Faculty of Economics UNIBA Surakarta. Brand Awareness partially influences positively and significantly the interest in buying Oppo Smartphones in UNIBA Surakarta Faculty of Economics Students. Celebrity Endorsement partially has a positive and significant influence on the Oppo Smartphone Interest in UNIBA Surakarta Faculty of Economics Students.
\end{abstract}

Keywords: Product quality, Brand Awarenesss,, Celebrity Endorsement, Purchase interest.

Abstrak : Penelitian ini bertujuan untuk mengetahui pengaruh Presepsi Kualitas Produk, Brand Awarenesss dan Celebrity Endorsement terhadap Minat Beli Oppo Smartphone pada Mahasiswa Fakultas Ekonomi UNIBA Surakarta. Jenis penilitian ini mengunakan metode kuantitatif, populasi yang diambil dalam penelitian ini adalah mahasiwa UNIBA Surakarta Sample yang dingunakan dalam penelitian ini adalah 80 orang, teknik pengambilan sampel dengan mengunakan teknik Purposive Sampling. Teknik analisis data dalam penelitian ini mengunakan teknik analisis Linier berganda. Hasil uji F menyatakan bahwa Presepsi Kualitas Produk, Brand Awarenesss dan Celebrity Endorsement secara simultan dan singnifikan berpengaruh terhadap Minat Beli Oppo Smartphone pada Mahasiswa Fakultas Ekonomi UNIBA Surakarta. sedangkan berdasarkan uji $t$ menyatakan bahwa secara parsial kualitas produk berpengaruh positif tidak signifikan terhadap Minat Beli Oppo Smartphone pada Mahasiswa Fakultas Ekonomi UNIBA Surakarta, Brand Awarenesss secara parsial berpengaruh positif dan signifikan Minat Beli Oppo Smartphone pada Mahasiswa Fakultas Ekonomi UNIBA Surakarta. Celebrity Endorsement secara parsial berpengaruh positif dan singnifikan terhadap Minat Beli Oppo Smartphone pada Mahasiswa Fakultas Ekonomi UNIBA Surakarta.

Kata kunci : Kualitas Produk, Brand Awareness, Celebrity Endorsement,Minat Pembelian 


\section{PENDAHULUAN}

Peradaban manusia yang semakin maju menyebabkan bertambahnya rutinitas aktivitas masyarakat.salah satunya Berkaitan dengan berkembangnya teknologi dan perekonomian yang kian pesat sehingga terjadi perubahan perilaku masyarakat, perlunya kebutuhan informasi.Yang akurat dan teruptodate menuntut perusahaan inovasioner dalam bidang teknologi harus bersaing ketat untuk menciptakan produk yang sesuai dengan permintaan konsumen baik itu smartphone. Hal ini terjadi karena meningkatnya pengunaan internet yang diimbangi dengan banyaknya jumlah penduduk di Indonesia, adanya smartphone bukan hanya sebagai alat komunikasi tetapi untuk meningkatkan prestige (gengsi) kepercayaan diri bagi penguna smartphone tersebut yang diperoleh dari beberapa hal seperti desain dan fitur smartphone yang ditawarkan oleh masyarakat (Hermanto dan Saputra, 2019). Berdasarkan perhitungan penjualan smartphone yang dilakukan oleh lembaga Survey IDC (Internasional Data Corporation) menyatakan bahwa pada tahun 2019 OPPO Smartphone berhasil menunjukan keandalanya dengan menguasai market pasar, hasil survei tersebut disimpulkan bahwa OPPO Smartphone dapat menyaingi produk Samsung Smartphone dengan menjadi urutan kedua dibandingkan produk lainya (www.seluler.id, 2019).

Berkembangnya produk smartphone yang lebih variatif dan canggih sehingga memunculkan berbagai motivasi atau minat konsumen untuk terus mencari dan membandingkan sebagai bahan pertimbangan dalam membeli, oleh karena itu perusahaan perlu mengembangkan strategi pemasaran yang bertujuan untuk memperluas market share (Powa, Lapean dan Wenas, 2018). Peningkatan kualitas produk merupakan dasar pengembangan produk, dalam penilaian yang dilakukan konsumen dapat diukur berdasarkan kepercayaan (reliability), ketahanan (durability) dan kinerja (performance), mudahnya mengoperasikan dan memeliharanya, serta atribut lain yang menunjang permintaan melalui kebutuhan konsumen. Perusahaan dalam menumbuhkan minat pembelian perlu adanya pemahaman bahwa konsumen akan mempunyai pandangan subyektif yang dimiliki terhadap suatu produk yang dipengaruhi oleh beberapa faktor yang bersifat intangible atau ekuitas merek, salah satunya, Brand Awareness atau kesadaran merek yang dimiliki konsumen, menjadi kesanggupan dari pembeli untuk mengenali mengingat kembali suatu merek sebagai bagian dari suatu kategori produk tertentu. Untuk menggambarkan keberadaan sebuah merek dalam pikiran konsumen yang telah dipengaruh oleh aktivitas promosi yang terintegrasi dalam meningatkan kesadaran merek yang bertujuan agar memperluas market pasar yang telah pada (Indayani, 2016). Untuk memperluas pengetahuan dan kesadaran produk pada konsumen adapun strategi pemasaran yang dingunakan untuk memperluas Segmen pasar yang dimiliki, melalui pengunaan promosi ataupun jasa adverdtising (iklan) Luzuardi (2018). Selain itu perusahaan dapat membentuk komunikasi kepada konsumen melalui artis pendukung atau celebrity endorsement yang diharapkan dapat mempresentasikan produk secara lebih jelas kepada konsumen sehingga memunculkan impulsive untuk membeli produk.

\section{LANDASAN TEORI Kualitas Produk}

Kualitas produk merupakan bagian dari keistimewaan produk yang digunakan untuk memunculkan kepuasaan konsumen dalam menggunakan produk tersebut (Laksana, 2010: 89) sedangkan menurut Oentoro, (2011) dalam menentukan kualitas produk terdapat pengukuran produk yang didasari dari keakuratan produk, Mudah pemeliharaan dan pemakainnya serta atribut pendukung lainya yang terdapat di suatu produk. 


\section{Brand Awareness}

Brand Awareness adalah kesadaran dari konsumen yang timbul untuk mengatur dan mengenal nama produk tersebut (Fadhilla dan Hidayat, 2018). Selain itu Brand Awareness merupakan petunjuk yang dingunakan calon pembeli termasuk bagian dari salah satu unsur keseluruhan produk, brand awareness membutuhkan waktu yang dilakukan secara bertahap dan kontinu agar konsumen yakin bahwa produk yang dipilih telah menjadi brand satu-satunya di suatu kelompok produk (Durianto et al., 2011: 4).

\section{Celebrity Edorsement}

Celebrity endorsement adalah suatu media periklanan yang bersifat umum dilakukan perusahaan dengan promosi melalui hubungan sosial secara langsung dengan sederet selebriti untuk memasarkan barang atau jasa, guna meningkatkan Brand Awareness terhadap konsumen (Grathwaite 2014: 76). Sedangkan menurut Rossiter dan Percy (2014: 53) celebrity endorsement merupakan suatu model iklan atau figure yang memiliki peran penting dalam mempengaruhi audience dalam iklan produk.

\section{KERANGKA PEMIKIRAN}

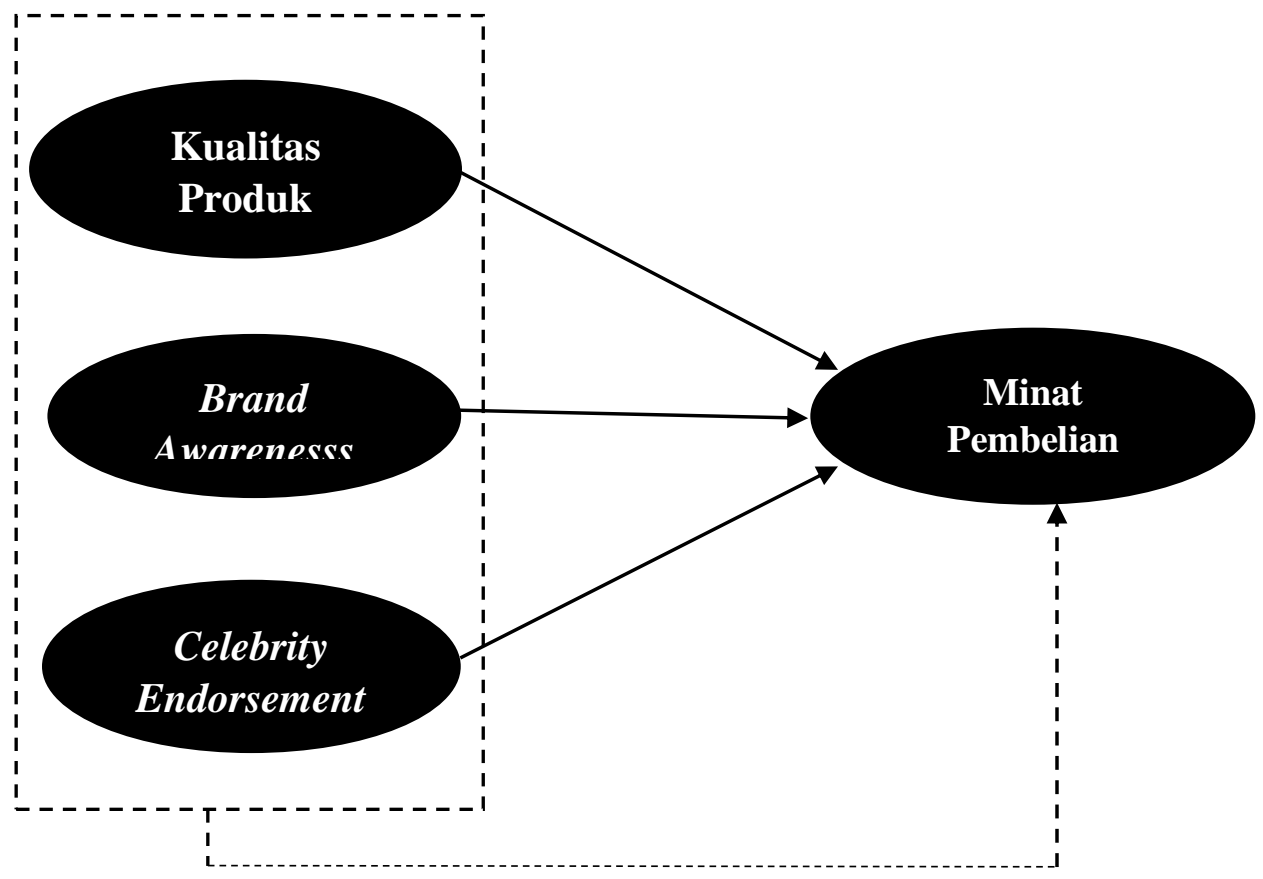

Gambar 1

Kerangka Pemikiran

\section{HIPOTESIS}

H1: Kualitas Produk berpengaruh positif berpengaruh positif dan signifikan terhadap minat pembelian konsumen OPPO smartphone pada mahasiswa fakultas ekonomi UNIBA Surakarta.

$\mathrm{H} 2$ : Brand Awareness berpengaruh positif dan signifikan terhadap minat pembelian konsumen OPPO Smartphone pada mahasiswa fakultas ekonomi UNIBA Surakarta. 
H3: Celebrity Endorsement berpengaruh positif dan signifikan terhadap minat pembelian konsumenOPPO Smartphone pada mahasiswa fakultas ekonomi UNIBA Surakarta.

\section{METODE PENELITIAN}

Jenis penelitian yaitu mengunakan penelitian kuantitatif, lokasi penelitian yang dilakukan berada di Universitas Islam Batik Surakarta dan objek penelitan ini adalah mahasiswa fakultas ekonomi UNIBA Surakarta, waktu penelitian dilaksanakan kurang lebih 6 bulan dari mulai Februari 2020 sampai Juli 2020, populasi yang diambil dalam penelitian ini terdapat 520 populasi dari keseluruhan mahasiswa dan mahasiswi fakultas ekonomi UNIBA Surakarta, sampel yang digunakan dalam penelitian ini ada 80 sampel pemilihan sampel ini mengunakan Purposive Sampling. Analisis data dalam penelitian ini diantaranya mengunakan uji asumsi kasik, uji linear berganda dan uji hipotesa.

\section{HASIL PENELITIAN DAN PEMBAHASAN}

a. Uji Asumsi Klasik

1) Uji Normalitas

Uji normalitas atau yang disebut Kolmogorov-Smirnov pengujian bertujuan untuk mengetahui model regresi dari variabel dependent dan variabel independent memiliki distribusi normal. Hal ini dapat dilihat dari apabila singnifikan variable > 5\% dan dan taraf signifikan alpha 5\% maka distribusi tersebut normal. Pada penelitian dapat dilihat dari tabel berikut:

Tabel 1 Uji Normalitas

One-Sample Kolmogorov-Smirnov Test

\begin{tabular}{|c|c|c|}
\hline & & $\begin{array}{l}\text { Unstandardized } \\
\text { Residual }\end{array}$ \\
\hline $\mathrm{N}$ & & 80 \\
\hline \multirow{3}{*}{ Normal Parameters ${ }^{\mathrm{a}, \mathrm{b}}$} & Mean & $0 \mathrm{E}-7$ \\
\hline & Std. Deviation & 1.71957721 \\
\hline & Absolute & .047 \\
\hline \multirow[t]{2}{*}{ Most Extreme Differences } & Positive & .047 \\
\hline & Negative & -.045 \\
\hline Kolmogorov-Smirnov Z & & .421 \\
\hline Asymp. Sig. (2-tailed) & & .994 \\
\hline
\end{tabular}

Berdasarkan pada tabel 1 diperoleh hasil pengujian Kolmogorov-Smirnov, Bahwa nilai Asym.sign (2-tailed) > 0,05 dari $(0,994>0,05)$ sehingga penelitian tersebut dinyatakan bahwa berdistribusi normal. 
2)Uji Multikolinieritas

Uji multikolenaritas dingunakan untuk menemukan hubungan kolerasi diantara varibel bebas dalam model regresi pada pengujian ini dapat ditentukan melalui nilai Variance Inflation Factor (VIF) dan nilai toleransi yang ada. Apabila nilai toleransi $>0,10$ dan nilai VIF $<10,00$ maka hasil penelitian tersebut tidak terdapat Multikolinieritas antar variabel bebasnya.

Tabel 2 Uji Multikolinieritas

\begin{tabular}{llllll}
\hline Variabel & Tolerensi & Kriteria & VIF & Kriteria & Keterangan \\
\hline Kualitas Produk & 0,654 & $>0,10$ & 1.529 & $<10,00$ & Tidak terjadi Multikolinieritas \\
Brand & 0,598 & $>0,10$ & 1.629 & $<10,00$ & Tidak terjadi Multikolinieritas \\
Awarenesss & 0,750 & $>0,10$ & 1.333 & $<10,00$ & Tidak terjadi Multikolinieritas \\
$\begin{array}{l}\text { Celebrity } \\
\text { Endorsement }\end{array}$ & & & & & \\
\hline
\end{tabular}

Dari tabel 2 ditentukan bahwa semua variabel bebas memiliki toleransi $>0,10$ dan VIF $<10,00$ sehingga dari pengujian tersebut dinyatakan tidak adanya gejala Multikolinieritas dalam model regresi penelitian ini.

3) Uji Heteroskadastisitas

Uji Heteroskedastisitas dingunakan untuk mengetahui ketidaksamaan varian dari residual dari suatu pengamatan satu sama lain dalam suatu model regresi. Pada pengujian ini dapat dilakukan dengan mengunakan uji glejser dengan cara meregresikan nilai absulote residual terhadap variabel independen, jika $p$-value $>0,05$ maka tidak terjadi heteroskadastisitas.

Tabel 3 Uji Heteroskadastisitas

\begin{tabular}{llll}
\hline \multicolumn{1}{c}{ Variabel } & $\begin{array}{c}\text { p-value } \\
\text { (sign })\end{array}$ & Batas & Keterangan \\
\hline Kualitas Produk & 0,077 & $>0,05$ & Tidak terjadi Heteroskedastisitas \\
Brand Awarenesss & 0,386 & $>0,05$ & Tidak terjadi Heteroskedastisitas \\
Celebrity endorsement & 0,352 & $>0,05$ & Tidak terjadi Heteroskedastisitas
\end{tabular}

Dari tabel 3 menunjukan bahwa dari ketiga variabel tersebut memiliki nilai $p$-value signifikan lebih dari 0,05 Jadi tidak terjadi Heteroskedastisitas atau berarti model regresi tersebut lulus uji Heteroskedastisitas dalam penelitian ini.

b. Uji Regresi Linear Regresi

Uji linear berganda dingunakan untuk mengetahui pengaruh dari variabel independen terhadap variabel dependen. Berikut hasil tabel analisis regresi linier berganda diantaranya: 


\section{Tabel 4 Uji T}

\begin{tabular}{lccc}
\hline \multicolumn{1}{c}{ Variabel } & T hitung & T tabel & Keterangan \\
\hline Kualitas produk & 0,742 & 1,991 & Ho diterima \\
Brand Awareness & 3.560 & 1,991 & Ho ditolak \\
$\begin{array}{l}\text { Celebrity } \\
\text { endorsement }\end{array}$ & 3.637 & 1,991 & Ho ditolak \\
\hline
\end{tabular}

Dari tabel 4 dapat diketahui persamaan linear antara kualitas produk, Brand Awareness dan celebrity endorsement terhadap minat pembelian terhadap minat pembelian yang ditunjuk sebagai berikut:

$$
\mathrm{Y}=4,445+0,060 \cdot X_{1}+0,314 \cdot X_{2}+0,292 \cdot X_{3}
$$

Kesimpulan dari hasil regresi linear berganda tersebut yaitu:

1) Konstanta (a): persamaan regresi memeiliki konstanta sebesar 4,445 yang berarti bahwa skor koefisien variabel kualitas produk (X1) Brand Awareness (X2) dan celebrity endorsement (X3) memiliki nilai $=$ konstan 0 , maka skor minat pembelian $(\mathrm{Y})$ akan meningkat dan cenderung kuat.

2) Koefisien $\left(b_{1}\right)$ : koefisien regresi yang dimiliki oleh variabel kualitas produk (X1) yaitu 0,060, hal menunjukan bahwa apabila koefisien variabel meningkat sebanyak 1 point maka, maka skor minat pembelian akan meningkat, sementara variabel Brand Awareness (X2) dan celebrity endorsement $(\mathrm{X} 3)=$ konstan.

3) Koefisien $\left(b_{2}\right)$ : koefisien regresi yang dimiliki oleh variabel Brand Awareness (X2) yaitu 0,314 yaitu hal menunjukan bahwa apabila koefisien variabel meningkat sebanyak 1 point maka, maka skor minat pembelian akan meningkat, sementara variabel kualitas produk (X1) dan celebrity endorsement $(\mathrm{X} 3)=$ konstan .

4) Koefisien $\left(b_{3}\right)$ : koefisien regresi yang dimiliki oleh variabel celebrity endorsement (X3) yaitu 0,292 , hal ini menunjukan bahwa apabila koefisien variabel meningkat sebanyak 1 point maka, maka skor minat pembelian akan meningkat, sementara variabel kualitas produk (X1) dan Brand Awareness (X2) = konstan.

c. Uji Hipotesis

1) Uji t (uji parsial)

Uji t parsial digunakan untuk menentukan hipotesis akan diterima atau ditolak dengan melihat tabel signifikansi.Hasil uji t secara ringkas ditentukan dalam tabel berikut: 


\section{Tabel .5 Uji t}

\begin{tabular}{lccc}
\hline \multicolumn{1}{c}{ Variabel } & t hitung & t tabel & Keterangan \\
\hline Kualitas produk & 0,742 & 1,991 & Ho diterima \\
Brand Awarenesss & 3.560 & 1,991 & Ho ditolak \\
Celebrity endorsement & 3.637 & 1,991 & Ho ditolak \\
\hline
\end{tabular}

a). Berdasarkan perhitungan pengujian variabel kualitas produk memiliki nilai t hitung $(0,743)$ $>\mathrm{t}$ tabel 1,991 dengan singnifikan $0,460<0,05$ artinya ho diterima, jadi secara parsial kualitas produk memiliki nilai positif tidak singnifikan berpengaruh terhadap minat pembelian OPPO smartphone pada mahasiswa fakultas ekonomi UNIBA Surakarta.

b). Berdasarkan pengujian variabel Brand Awareness memiliki nilai t hitung $(3,560)>\mathrm{t}$ tabel 1,991 dengan singnifikan 0,01 $<0,05$ artinya ho ditolak, jadi secara parsial Brand Awareness memiliki nilai positif dan singnifikan berpengaruh terhadap minat pembelian OPPO smartphone pada mahasiswa fakultas ekonomi UNIBA Surakarta.

c). Berdasarkan pengujian variabel celebrity endorsement memiliki nilai t hitung $(3,632)>\mathrm{t}$ tabel 1,991 dengan singnifikan 0,01 <0,05 artinya ho ditolak, jadi secara parsial celebrity endorsement memiliki nilai positif dan singnifikan berpengaruh terhadap minat pembelian OPPO smartphone pada mahasiswa fakultas ekonomi UNIBA Surakarta.

2) Uji F (Uji Simultan)

Uji F digunakan untuk menunjukkan semua variabel bebas yang dimasukkan dalam model mempunyai pengaruh secara bersama-sama terhadap variabel terikat, Hasil uji F secara ringkas ditunjukkan dalam tabel berikut:

Tabel 6 Uji F

\begin{tabular}{cccccc}
\hline Model & F hitung & F tabel & Signifikan & Std & Keterangan \\
\hline $\mathbf{1}$ & 22.003 & 2,72 & 0,00 & 0,05 & Mode layak \\
\hline
\end{tabular}

Dalam pengujian ini dapat diketahui f hitung $(22,003)>\mathrm{f}$ tabel $(2,72)$ dengan nilai singnifikan $0,00<0,05$ maka dapat ditentukan Ho ditolak yang berarti presepsi kualitas produk, Brand Awareness dan celebrity endorsement secara simultan berpengaruh terhadap minat pembelian konsumen OPPO smartphone pada mahasiswa fakultas ekonomi UNIBA Surakarta.

\section{3) Uji Koefisien Determinan}

Uji koefisien determinan adalah alat uji yang dipakai untuk mengukur seberapa besar kontribusi yang dapat dihasilkan oleh variabel dependen dan variabel independen. Berikut hasil perhitungan dari uji $\mathrm{F}$ yaitu: 
Tabel 7 Uji Koefisien Determinan Model Summary ${ }^{b}$

\begin{tabular}{|l|r|r|r|r|r|}
\hline Model & \multicolumn{1}{|c|}{$\mathrm{R}$} & $\mathrm{R}$ Square & $\begin{array}{c}\text { Adjusted R } \\
\text { Square }\end{array}$ & $\begin{array}{c}\text { Std. Error of } \\
\text { the Estimate }\end{array}$ & $\begin{array}{c}\text { Durbin- } \\
\text { Watson }\end{array}$ \\
\hline 1 & $.682^{\mathrm{a}}$ & .465 & .444 & 1.753 & 2.332 \\
\hline
\end{tabular}

a. Predictors: (Constant), CE, KP, BA

b. Dependent Variable: MBK

Dari pengujian tersebut, koefisien determinan ditunjukan sebesar 0,444 sehingga nilai $R^{2}$ menunjukan variabel presepsi kualitas produk, Brand Awareness dan celebrity endorsement saling berkontribusi sebesar 44,4\% terhadap minat pembelian OPPO smarphone. Sementara sisanya oleh dijelaskan oleh variabel lainya yang tidak terdapat dalam penelitian ini.

\section{Pembahasan}

Hasil penelitian ini menunjukan bahwa:

1) Pengaruh Kualitas Produk (X1) terhadap Minat Pembelian (Y)

pada hasil penelitian tersebut dapat diperoleh hasil bahwa variabel kualitas produk berpengaruh positif tidak signifikan terhadap minat pembelian konsumen OPPO smartphone pada mahasiswa fakultas ekonomi UNIBA Surakarta. Penelitian ini sejalan dengan hasil penelitian Hermanto dan Saputra, (2019), kedua peneliti tersebut menyatakan bahwa kualitas produk tidak berpengaruh terhadap minat pembelian.

2) Pengaruh Brand Awareness (X2) terhadap Minat Pembelian (Y)

Pada hasil penelitian tersebut dapat diperoleh hasil bahwa variabel Brand Awareness berpengaruh positif dan signifikan terhadap minat pembelian konsumen OPPO smartphone pada mahasiswa fakultas ekonomi UNIBA Surakarta. Penelitian in didukung oleh penelitian dari Fadhilla dan Hidayat, (2018) dari penelitian kedua peneliti tersebut menyatakan bahwa variabel Brand Awareness memiliki pengaruh terhadap minat pembelian.

3) Pengaruh Celebrity Endorsement (X3) Terhadap Minat Pembelian Konsumen (Y)

Pada hasil penelitian tersebut dapat diperoleh hasil bahwa variabel Celebrity Endorsement berpengaruh positif dan signifikan terhadap minat pembelian konsumen OPPO smartphone padaPmahasiswa fakultas ekonomi UNIBA Surakarta. Penilitian ini mendukung dari penelitian sebelumnya oleh Iwan dan Nainggolan (2017) dalam penelitian tersebut peneliti menyatakan bahwa variabel Celebrity endorsement memiliki pengaruh terhadap minat pembelian.

\section{KESIMPULAN}

Berdasarkan hasil penelitian ini dapat diketahui bahwa :

1) Melalui hasil koefesien determinan dapat diperoleh hasil yaitu sebanyak $44 \%$ yang berarti kualitas produk, Brand Awareness dan celebrity endorsement terdapat kontribusiterhadap minat pembelian OPPO smartphone sedangkan sisanya dijelaskan dalam variabel lainnya yang tidak terdapat penelitian ini.

2) Dari ketiga variabel yaitu kualitas produk, Brand Awareness dan celebrity endorsement secara simultan memiliki pengaruh terhadap minat pembelian OPPO smartphone. 
Ayu Intan Pratiwi, Bambang Mursito, Eny Kustiyah / Edunomika Vol. 04, No. 02, 2020

3) Berdasarkan hasil uji t dapat disimpulkan bahwa untuk kualitas produk secara parsial tidak berpengaruh terhadap minat pembelian,sedangkan,Brand Awareness dan celebrity endorsement secara parsial memiliki pengaruh terhadap minat pembelian OPPO smartphone.

\section{SARAN}

Adapun saran diberikan pada penelitian ini hendaknya dapat dingunakan dalam bidang akedemis dengan untuk sebagai landasan bahan penelitian selanjutnya pada perusahaan sejenis dengan mengembang penelitian agar lebih luas dan selain itu dapat dingunakan sebagai perusahaan agar dapat mengembangkan dibidang pemasaran untuk meningkatkan minat pembelian pada OPPO smartphone

\section{DAFTAR PUSTAKA}

Aaker, D. (1997). Manajemen Ekuitas Merek. Jakarta: Spektrum Mitra Utama.

Ambadar, J., Abidin, M., \& Ira , Y. (2007). Mengelola Merek. Jakarta: Yayasan Bina Karsa Mandiri.

Bastian, A., Sugito, Kerinus Hati, W., Nastiti, W., \& Sustiwati Sirait, L. (2019). The Influence Of Advertising Stars, Brand Image, And Brand Awarenesss On The Intention To Buy Honda Vario Motorcycles In Pasuruan. Sinergi, 9(1), 43-50.

Cl, G. (2014). Demand Spillovers, Combative Advertising, And Celebrity Endorsements. AmeriCan Economic Journal: Applied Economics, 6(2), 76-104.

Dinawan. (2010). Kualitas Produk : Alat Strategi Yang Penting. Jakarta: Raja Grafindo Persada.

Durianto, D., Budiman , S., \& Joko, L. (2004). Brand Equity Ten. Jakarta: Pt Gramedia Pustaka Utama.

Fadhilla, Z. ,., \& Hidayat, R. (2018). Pengaruh Brand Awarenesss Terhadap Minat Beli Smartphone Merek Iphone Pada Konsumen Generasi “Z” Tahun. E-Proceeding Of Applied Science, 4(3), 1027-1033.

Ghozali, I. (2016). Aplikasi Analisis Multivariate Dengan Program Ibm Spss 21 Update Pls Regresi Edisi 7. Semarang: Badan Penerbit Undip.

Hermanto Saputra Rendy. (2019). Pengaruh Citra Merek Dan Kualitas Produk Terhadap Minat Beli Konsumen Produk Smartphone Xiaomi (Studi Kasus Di Jakarta Barat). Business Management Journal, 15(1), 1-67.

Indonesia, O. S. (2018). Oppo Smartphone Indonesia (. Retrieved From Www.Opposmartphonecp.

Khoirunnisa. (2019, 7 30). Idc: Top 5 Vendor Smartphone Indonesia Q2-2019. Retrieved From Www. Seluler. Id.: Https://Selular.Id/2019/08/Idc-Top-5-Vendor-Smartphone-IndonesiaQ2-2019/\#: :Text=Hari\%20ini\%20(30\%2f8), Realme\%20(6\%2c1\%25). 
Ayu Intan Pratiwi , Bambang Mursito, Eny Kustiyah / Edunomika Vol. 04, No. 02, 2020

Kirby Naribia, A. D., \& Iskandar, D. (2017). Pengaruh Celebrity Endorser Jkt48 Terhadap Minat Beli Konsumen Im3 Play (Studi Kasus Pada Pengunjung Teater Jkt48 Periode 21 Februari 2016). E-Proceeding Of Management, 4(2), 1304-1311.

Kotler, P., \& Armstrong, G. (2013). Principles Of Marketing (Fourteenth Edition). England: Pearson Education Limited.

Laluyan, W. N., \& Pangemanan, S. S. (2017). The Effect Of Advertising, Perceived Quality And Brand Awarenesss On Consumer Purchase Intention (Case Study: Adidas Sport Shoes). Emba, 5(2), 267-278.

Lazuardi, D. (2018). Pengaruh Celebrity Endorser Dan Iklan Terhadap Minat Beli Sepatu Olahraga Nike (Studi Kasuspada Mahasiswa Stie Eka Prasetya). Riset Manajemen \& Bisnis (Jrmb, $3(2), 1-7$.

Manorek Langling, S. (2016). The Influence Of Brand Image, Advertising Perceived Price Toward Consumer Purchase Intention (Case Study. Berkala Ilmiah Efisiensi, 16(1), 661-670.

Maryam, S. (Statustik Induktif). 2011. Surakarta: Uniba Press.

Nainggolan Kaman, I. (2017). Pengaruh Celebrity Endorser, Brand Awarenesss Dan Harga Produk Terhadap Minat Beli Mie Suksess (Studi Kasus Empiris Pada Penduduk Kecamatan Pinang-Kota Tangerang). Cakrawala, 17(2), 146-155.

Pandjaitan Haratua, R. D. (2018). An Analysis Of Brand Awarenesss Influence On Purchase Intention In Bandar Lampung City'sonline Transportation Service (Study On Y Generation Consumers). Icoi-The International Conference Of Organizational Innovation., 726-728.

Powa, A. G. (2018). Pengaruh Kualitas Produk, Harga Dan Word Of Mouth Terhadap Minat Beli Konsumen Handphone Pada Mahasiswa Feb Unsrat. . Jurnal Emba, 6(3), 1188-1197.

Pradana Anugrah, F. T. (2015). Brand Awarenesss Terhadap Minat Beli Konsumen Jasa Reservasi Hotel Secara Online Pada Situs Www.Goindonesia.Com,. E-Proceeding Of Management, 2(3), 611-2619.

Retnowulan, J. (2017.). Pengaruh Kualitas Produk Dan Persepsi Harga Terhadap Minat Beli Smartphone Xiaomi, Cakrawala. Cakrawala, 17(2), 139-145.

Setiawan, L. (2018). Pengaruh Celebrity Endorsement Terhadap Purchase Intention Dengan Brand Awarenesss Sebagai Variabel Mediasi Pada Produk Green Tea Esprecielo Allure. Manajemen Pemasaran, 12(1), 53-60.

Setu, F. (2019, 11 26). Menkominfo Pastikan Indonesia Siap Menjadi Negara Digital Tahun 2035. Retrieved From Www.Kominfo.Go.Id.

Shimp, T. A. (2007). Periklanan Promosi (Aspek Tambahan Komunikasi Pemasaran Terpadu). Jilid I, Edisi Terjemahan. Jakarta: Pt. Erlangga.

Sugiyono. (2011). Metode Penelitian Kuantitatif, Kualitatif Dan. Bandung : Alfabeta.

Swastha, B. D. (2012). Manajemen Modern, Edisi Kedua, Cetakan Kesebelas. Yogyakarta: Liberty Offset. 
Takaya, R. (2017). The Effect Of Celebrity Endorsment On Brand Image And Trust Brand And It's Impact To Purchaseintention Case Study: Oppo Smartphone. Business And Entrepreneurial Review, 17(2), 83-196.

Utarsih, H. (2014). Pengaruh Celebrity Endorser Terhadap Minat Beli Kartu As. Jurnal Ilman, 1(2), 105-112.

Widarto, R. (2018). The Influence Of Celebrity Endorsements On Purchase Intention (A Study On Vivo V7). . Iosr Journal Of Business And Management, 20(8), 59-66. 